\title{
The influence of environmental constraints within hospitals on physical activity level of cancer patients
}

\author{
Ik Young Chang', Eun-Surk Yi,** \\ ${ }^{1}$ Department of Community Sport, Korea National Sport University, Seoul, Korea \\ ${ }^{2}$ Department of Exercise Rehabilitation and Welfare, College of Health Science, Gachon University, Incheon, Korea
}

This study aims to examine the influence of hospital environmental constraints on physical activity level of cancer patients. The subjects of this study were 194 cancer patients from five general hospitals in the Seoul metropolitan area (Seoul, Gyeonggi-do, and Incheon). The collected data was analyzed by using SPSS ver. 23.0. As a result of analyzing the effect of environmental constraints on the physical activity level of cancer patients, the constraints related to hospital facilities and programs had no effect on patients' time spent in a hospital bed and their time spent on daily. However, the time cancer patients spend on intentional physical movements is affected by hospital facilities or programs. This means that hospital facilities or programs play an important role in patients' intentional physical activities. In conclusion, for hospitalized cancer patients, physical activity levels are influenced by environmental constraints in the hospital. Therefore, it is important to improve the hospital environment to increase physical activities such as walking and physical exercise, which are an important factor for cancer recovery and prevention of recurrence.

Keywords: Hospital, Environmental constraints, Physical activity, Cancer, Patients

\section{INTRODUCTION}

Approximately 8.7 million people around the world die from cancer every year (Global Burden of Disease Cancer Collaboration et al., 2017). In providing medical services in a hospital, physical activity has been considered an important factor for patients facing various diseases. Existing studies (Clark et al., 2008; Martin et al., 2009; Meyerhardt et al., 2006; Peddle et al., 2008) that particularly emphasize the benefit of physical activities for recovering patients with cancer have become more important today. Despite the advantages of physical activities, inpatients with cancers, in fact, have a lot of limitations in participating in physical activities due to limitations of the physical environment within a hospital.

According to Weiderpass (2010), 35\% of cancer patients, or 3 million lives, could have been saved by physical environment changes. In other words, providing an appropriate environment within the hospital for the physical activities of cancer patients can contribute significantly in helping cancer patients recover from their surgeries and further preventing the recurrence of cancer. Based on these study results, efforts to improve the physical environment within the hospital for cancer patients are undoubtedly crucial (Yang et al., 2015).

Despite evidence supporting the importance of the physical environment in the hospital for cancer patients, the scope of many existing studies is limited to: the effect of physical activities on cancer recurrence (Friedenreich et al., 2010; Oechsle et al., 2014; Persoon et al., 2013; Wiskemann et al., 2014), the effect of physical activities prior to and after cancer surgery (O'Doherty et al., 2013; Singh et al., 2013; West et al., 2015), and the effect after cancer treatments (Kim et al., 2009). There is insufficient analysis of the constraints of patients' physical activities due to the limitations of current medical services.

Therefore, this study focuses on analyzing the influence of environmental constraints in the hospital on the level of inpatients' physical activities during hospitalization and identifying the physical space limitations of hospitals in South Korea that may af-
${ }^{*}$ Corresponding author: Eun-Surk Yi iD https://orcid.org/0000-0002-9370-5231 Department of Exercise Rehabilitation and Welfare, College of Health Science, Gachon University, 191 Hambangmoe-ro, Yeonsu-gu, Incheon 21936, Korea Tel: +82-32-820-4442, Fax +82-32-820-4442, E-mail: yies@gachon.ac.kr Received: April 1, 2018 / Accepted: May 10, 2018
This is an Open Access article distributed under the terms of the Creative Commons Attribution Non-Commercial License (http://creativecommons.org/licenses/by-nc/4.0/) which permits unrestricted non-commercial use, distribution, and reproduction in any medium, provided the original work is properly cited. 
fect the patients' physical activities. In particular, an empirical study was conducted to verify the physical space constraints patients face in the hospital as the existing studies articulate the importance of cancer patients' physical activities for their recovery and prevention of recurrence while lacking fundamental supporting evidence.

\section{MATERIALS AND METHODS}

\section{Study subjects}

In order to analyze the effect of environmental constraints in the hospital on the level of cancer patients' physical activities, the study subjects — cancer patients who are older than 20 years oldwere selected from five general hospitals in the Seoul metropolitan area (Seoul, Gyeonggi-do, and Incheon). The data was collected with a survey conducted on 250 cancer patients from a population selected by purposive sampling. The survey was conducted from March to May 2017, and a total of 194 survey results were used in the final analysis, excluding 56 surveys with disqualifying responses such as unfaithful answers and double or missing entries.

\section{Table 1. Demographic characteristic}

\begin{tabular}{lc}
\hline Variable & No. of subjects (\%) \\
\hline Sex & \\
Male & $72(37.1)$ \\
Female & $122(62.9)$ \\
Age (yr) & \\
$<40$ & $8(4.1)$ \\
In 40s & $32(16.5)$ \\
In 50s & $69(35.6)$ \\
In 60s & $48(24.7)$ \\
$\geq 70$ & $37(19.1)$ \\
Cancer diagnosis & \\
Breast cancer & $51(26.3)$ \\
Colon cancer & $33(17)$ \\
Gastric cancer & $20(10.3)$ \\
Uterine cancer & $11(5.7)$ \\
Lung cancer & $11(5.7)$ \\
Rectal cancer & $9(4.6)$ \\
Leukemia & $9(4.6)$ \\
Brain tumor & $8(4.1)$ \\
Other* & $42(21.7)$ \\
Total & $194(100)$ \\
\hline
\end{tabular}

* Other types of cancer: liver cancer (6), lymphoma (6), blood cancer (5), ovarian cancer (5), myeloma (3), gallbladder cancer (2), dermatofibrosarcoma (2), thyroid cancer (2), spinal tumor (2), head and neck cancer (2), cerebral infarction (1), brain cancer (1), pancreatic cancer (1), osteosarcoma (1), biliary cancer (1), esophageal cancer (1), pharynx cancer (1).
Table 1 shows the demographic characteristics of the subjects.

\section{Research tools}

To analyze the effect of environmental constraints in the hospital on the level of cancer patients' physical activities, this study conducted surveys of cancer patients. The first three questions on their sex, age, and diagnosis were used to understand the demographic characteristics of the subjects. Eight questions regarding environmental constraints in hospitals were modified versions of the questions used in the existing studies of Zhu (2001). The last three questions were used to assess the level of cancer patients' physical activities. The questions consisted of responses regarding three types of activities in terms of patients' time spent in a hospital: (a) Time spent in a hospital bed (sleeping, watching TV, reading books, and others), (b) Time spent for daily maintenance (eating meals, washing, dressing and others), and (c) Time spent on intentional physical movement (walking, physical exercise, and others).

\section{Reliability and validity of the questionnaire}

This study conducted exploratory factor analysis to verify the reliability and validity of the survey results. In order to determine constructive factors, this study used principal component analysis, and to simplify factor qualifications, Varimax rotation was selected. Furthermore, the Kaiser-Meyer-Olkin (KMO) measure of sample adequacy was used for factor analysis. Bartlett's test of sphericity $\left(\chi^{2}\right)$ was used for indicating correlation matrices suitable for factor analysis. Question responses were developed by selecting variables with an eigenvalue higher than 1.0.

As a result of exploratory factor analysis, three factors of hospital facilities constraint and four factors of hospital program constraint were identified.

The environmental constraints within the hospital had $\mathrm{KMO}=$ 0.724 and $\chi^{2}=340.928$, and in terms of the eigenvalues of hospital facility constraints, the value was 2.695 (variance \%: 38.494 ) while the eigenvalues of hospital program constraints were 1.587 (variance \%: 22.673). All factor loadings were based on 0.05 or higher. As a result, one item of the hospital facility constraint factors was removed from eight items of environmental constraints within the hospital. Cronbach a coefficient was used to measure the reliability of each variable. The hospital facility constraint factor was 0.763 and hospital program constraint factor was 0.640 .

\section{Data analysis}

The purpose of this study was to investigate the effect of envi- 
ronmental constraints on the level of physical activity in cancer patients. In order to conduct the survey, we first requested the collaboration of hospital staff, and researchers and research assistants visited the hospital and met the cancer patients in person to thoroughly explain the purpose and methodology of the survey. The questionnaire was prepared with a self-assessment method. The collected survey data excluded any disqualifying responses such as double or no entry. The qualifying survey data was imported to a computer by independent coding and a statistical program, IBM SPSS Statistics ver. 23.0 (IBM Co., Armonk, NY, USA), was used to conduct analyses such as frequency analysis, exploratory factor analysis, reliability analysis, correlation analysis, and multiple regression analysis.

\section{RESULTS}

\section{Correlations among the variables}

To verify the relationships among variables, this study exam-

Table 2. Correlation analysis

\begin{tabular}{cccccc}
\hline & $\mathrm{a}$ & $\mathrm{b}$ & $\mathrm{c}$ & $\mathrm{d}$ & $\mathrm{e}$ \\
\hline $\mathrm{a}$ & 1.000 & & & & \\
$\mathrm{~b}$ & $0.274^{* *}$ & 1.000 & & & \\
$\mathrm{c}$ & 0.119 & 0.056 & 1.000 & & \\
$\mathrm{~d}$ & -0.042 & -0.089 & 0.088 & 1.000 & \\
$\mathrm{e}$ & $0.327^{* *}$ & $0.225^{* *}$ & -0.033 & $0.161^{*}$ & 1.000 \\
\hline
\end{tabular}

a, hospital facility constraint; $b$, hospital program constraint; $c$, time spent in a hospital bed; $d$, time spent for daily maintenance; e, time spent on intentional physical movement.

${ }^{*} P<0.05 .{ }^{*} P<0.01$. ined the correlation between each subvariable and analyzed the correlation to confirm multicollinearity. As shown in Table 2, the results show correlations between variables at a level of $P<0.05$. Furthermore, correlation coefficients between the sub-variables were relatively low (less than 0.80 ), so there was no issue with multicollinearity. Therefore, the analyses confirmed that each variable is mutually independent. As shown in Table 2, hospital facility constraints were significantly correlated with hospital program constraints and patients' time spent on intentional physical movement. In addition, hospital program constraints were positively correlated with patients' time spent on intentional physical movement, and there was also a statistically significant correlation between patients' time spent on daily maintenance and intentional physical movement.

\section{Multiple regression analysis of hospital environmental constraints on the level of physical activity of cancer patients}

To identify the effect of environmental constraints on the physical activity level of cancer patients, multiple regression analysis was performed, and the results are shown in Table 3.

The results in Table 3 show that first, the environmental constraints in the hospital did not affect the physical activity level of cancer patients during the time they spent in a hospital bed, as the descriptive power was $1.5 \%$.

Second, the environmental constraints in the hospital did not affect the cancer patients' physical activity level during their time spent on daily maintenance, as the descriptive power was approximately $0.8 \%$.

Table 3. Multiple regression analysis of the effects of hospital environment constraints on physical activity of cancer patients

\begin{tabular}{|c|c|c|c|c|c|}
\hline \multirow{2}{*}{ Variable } & \multicolumn{2}{|c|}{ Unstandardized factor } & \multirow{2}{*}{$\begin{array}{c}\text { Standardized factor } \\
\beta\end{array}$} & \multirow{2}{*}{$t$} & \multirow{2}{*}{$P$-value } \\
\hline & B & Standard error & & & \\
\hline \multicolumn{6}{|l|}{ Time spent in hospital bed } \\
\hline Hospital facility constraints & 0.136 & 0.091 & 0.112 & 1.504 & 0.134 \\
\hline Hospital program constraints & 0.029 & 0.086 & 0.025 & 0.340 & 0.734 \\
\hline \multicolumn{6}{|l|}{$F=1.438, R^{2}=0.015$} \\
\hline \multicolumn{6}{|l|}{ Time spent for daily maintenance } \\
\hline Hospital facility constraints & -0.024 & 0.098 & -0.019 & -0.249 & 0.804 \\
\hline Hospital program constraints & -0.104 & 0.093 & -0.084 & -1.117 & 0.265 \\
\hline \multicolumn{6}{|l|}{$F=0.791, R^{2}=0.008$} \\
\hline \multicolumn{6}{|c|}{ Time spent on intentional physical movement } \\
\hline Hospital facility constraints & 0.470 & 0.115 & 0.286 & 4.071 & 0.000 \\
\hline Hospital program constraints & 0.228 & 0.109 & 0.147 & 2.087 & 0.038 \\
\hline$F=13.839^{* * *}, R^{2}=0.127$ & & & & & \\
\hline
\end{tabular}

${ }^{* * *} P<0.001$. 
However, the environmental constraints in the hospital had an effect on the cancer patients' physical activity level during their time spent on intentional physical movement, with a descriptive power of approximately $12.7 \%$. In terms of the environmental effects on patients' physical activities in the hospital, relative importance was found to be in the order of hospital facility constraint $(\beta=0.286)$ and hospital program constraint $(\beta=0.147)$.

\section{DISCUSSION}

This empirical study focused on analyzing the effect of environmental constraints of the hospital on the level of cancer patients' physical activity, and based on the collected data, the results of analyses are as follows:

As a result of analyzing the effect of environmental constraints on the physical activity level of cancer patients, the constraints related to hospital facilities and programs had no effect on patients' time spent in a hospital bed and their time spent on daily maintenance such as eating meals, washing, and putting on clothes. In other words, regardless of the type of hospital facility or program put in place, the level of patients' physical activities is unaffected. However, the time cancer patients spend on intentional physical movements is driven by hospital facilities or programs. Existing studies assert that hospital facilities or programs are important factors that affect patients' intentional physical activities, and thus, patients' recovery (Codinhoto et al., 2009; Devlin and Arneill, 2003; Huisman et al., 2012). In the same vein, the physical environment of a hospital has a crucial impact on promoting or inhibiting the physical activity of cancer patients. Therefore, as existing studies find that physical activity is an important factor in cancer treatment and the prevention of cancer recurrence, it is necessary that hospitals host an appropriate environment for patients in the effort for cancer treatment and recurrence prevention (Jonas and Chez, 2004; Ulrich, 1992).

In conclusion, for hospitalized cancer patients, physical activity levels are influenced by environmental constraints in the hospital. In particular, it is important to improve the hospital environment to increase physical activities such as walking, which is an important factor for cancer recovery and prevention of recurrence.

Above all, it is important to remember that a more detailed analysis of the characteristics of environmental constraints in hospitals can substantially enhance medical services for cancer patients. Based on the analysis results, this study recommends the following. Since this study did not consider differences in cancer diagnosis characteristics, subsequent studies may conduct in- depth analyses of the medical condition of a hospitalized cancer patient in the hospital considering the possibility that environmental constraints in the hospital may differ by the characteristics of different cancers. Furthermore, this study was limited to analyze the staff members of the hospital in improving the hospital environment. Thus, further research is needed to investigate in depth why hospitals fail to improve the environment in their hospitals, despite widely known existing study results on the benefits of physical activity for the recovery of cancer patients. The findings would contribute greatly to the improvement of the hospital environment for cancer inpatients.

\section{CONFLICT OF INTEREST}

No potential conflict of interest relevant to this article was reported.

\section{ACKNOWLEDGMENTS}

This work was supported by the Ministry of Education of the Republic of Korea and the National Research Foundation of Korea (NRF-2016S1A5B6913737).

\section{REFERENCES}

Clark MM, Novotny PJ, Patten CA, Rausch SM, Garces YI, Jatoi A, Sloan JA, Yang P. Motivational readiness for physical activity and quality of life in long-term lung cancer survivors. Lung Cancer 2008;61:117-122.

Codinhoto R, Tzortzopoulos P, Kagioglou M, Aouad G, Cooper R. The impacts of the built environment on health outcomes. Facilities 2009; 27:138-151

Devlin AS, Arneill AB. Health care environments and patient outcomes. a review of literature. Environ Behav 2003;35:665-694.

Friedenreich CM, Woolcott CG, McTiernan A, Ballard-Barbash R, Brant RF, Stanczyk FZ, Terry T, Boyd NF, Yaffe MJ, Irwin ML, Jones CA, Yasui Y, Campbell KL, McNeely ML, Karvinen KH, Wang Q, Courneya KS. Alberta physical activity and breast cancer prevention trial: sex hormone changes in a year-long exercise intervention among postmenopausal women. J Clin Oncol 2010;28:1458-1466.

Global Burden of Disease Cancer Collaboration, Fitzmaurice C, Allen C, Barber RM, Barregard L, Bhutta ZA, Brenner H, Dicker DJ, ChimedOrchir O, Dandona R, Dandona L, Fleming T, Forouzanfar MH, Hancock J, Hay RJ, Hunter-Merrill R, Huynh C, Hosgood HD, Johnson CO, Jonas JB, Khubchandani J, Kumar GA, Kutz M, Lan Q, Larson HJ, Liang X, Lim SS, Lopez AD, MacIntyre MF, Marczak L, Marquez N, 
Mokdad AH, Pinho C, Pourmalek F, Salomon JA, Sanabria JR, Sandar L, Sartorius B, Schwartz SM, Shackelford KA, Shibuya K, Stanaway J, Steiner C, Sun J, Takahashi K, Vollset SE, Vos T, Wagner JA, Wang H, Westerman R, Zeeb H, Zoeckler L, Abd-Allah F, Ahmed MB, Alabed S, Alam NK, Aldhahri SF, Alem G, Alemayohu MA, Ali R, Al-Raddadi R, Amare A, Amoako Y, Artaman A, Asayesh H, Atnafu N, Awasthi A, Saleem HB, Barac A, Bedi N, Bensenor I, Berhane A, Bernabé E, Betsu B, Binagwaho A, Boneya D, Campos-Nonato I, Castañeda-Orjuela C, Catalá-López F, Chiang P, Chibueze C, Chitheer A, Choi JY, Cowie B, Damtew S, das Neves J, Dey S, Dharmaratne S, Dhillon P, Ding E, Driscoll T, Ekwueme D, Endries AY, Farvid M, Farzadfar F, Fernandes J, Fischer F, G/Hiwot TT, Gebru A, Gopalani S, Hailu A, Horino M, Horita N, Husseini A, Huybrechts I, Inoue M, Islami F, Jakovljevic M, James S, Javanbakht M, Jee SH, Kasaeian A, Kedir MS, Khader YS, Khang YH, Kim D, Leigh J, Linn S, Lunevicius R, El Razek HMA, Malekzadeh R, Malta DC, Marcenes W, Markos D, Melaku YA, Meles KG, Mendoza W, Mengiste DT, Meretoja TJ, Miller TR, Mohammad KA, Mohammadi A, Mohammed S, Moradi-Lakeh M, Nagel G, Nand D, Le Nguyen Q, Nolte S, Ogbo FA, Oladimeji KE, Oren E, Pa M, Park EK, Pereira DM, Plass D, Qorbani M, Radfar A, Rafay A, Rahman M, Rana SM, Søreide K, Satpathy M, Sawhney M, Sepanlou SG, Shaikh MA, She J, Shiue I, Shore HR, Shrime MG, So S, Soneji S, Stathopoulou V, Stroumpoulis K, Sufiyan MB, Sykes BL, Tabarés-Seisdedos R, Tadese F, Tedla BA, Tessema GA, Thakur JS, Tran BX, Ukwaja KN, Uzochukwu BSC, Vlassov VV, Weiderpass E, Wubshet Terefe M, Yebyo HG, Yimam HH, Yonemoto N, Younis MZ, Yu C, Zaidi Z, Zaki MES, Zenebe ZM, Murray CJL, Naghavi M. Global, regional, and national cancer incidence, mortality, years of life lost, years lived with disability, and disability-adjusted life-years for 32 cancer groups, 1990 to 2015: a systematic analysis for the global burden of disease study. JAMA Oncol 2017;3:524-548.

Huisman ER, Morales E, van Hoof J, Kort HS. Healing environment: a review of the impact of physical environmental factors on users. Build Environ 2012;58:70-80.

Jonas WB, Chez RA. Toward optimal healing environments in health care. J Altern Complement Med 2004;10 Suppl 1:S1-6.

Kim CJ, Kang DH, Park JW. A meta-analysis of aerobic exercise interventions for women with breast cancer. West J Nurs Res 2009;31:437-461.

Martin CK, Church TS, Thompson AM, Earnest CP, Blair SN. Exercise dose and quality of life: a randomized controlled trial. Arch Intern

\section{Med 2009;169:269-278.}

Meyerhardt JA, Heseltine D, Niedzwiecki D, Hollis D, Saltz LB, Mayer RJ, Thomas J, Nelson H, Whittom R, Hantel A, Schilsky RL, Fuchs CS. Impact of physical activity on cancer recurrence and survival in patients with stage III colon cancer: findings from CALGB 89803. J Clin Oncol 2006;24:3535-3541.

O'Doherty AF, West M, Jack S, Grocott MP. Preoperative aerobic exercise training in elective intra-cavity surgery: a systematic review. Br J Anaesth 2013;110:679-689.

Oechsle K, Aslan Z, Suesse Y, Jensen W, Bokemeyer C, de Wit M. Multimodal exercise training during myeloablative chemotherapy: a prospective randomized pilot trial. Support Care Cancer 2014;22:63-69.

Peddle CJ, Au HJ, Courneya KS. Associations between exercise, quality of life, and fatigue in colorectal cancer survivors. Dis Colon Rectum 2008; 51:1242-1248.

Persoon S, Kersten MJ, van der Weiden K, Buffart LM, Nollet F, Brug J, Chinapaw MJ. Effects of exercise in patients treated with stem cell transplantation for a hematologic malignancy: a systematic review and meta-analysis. Cancer Treat Rev 2013;39:682-690.

Singh F, Newton RU, Galvão DA, Spry N, Baker MK. A systematic review of pre-surgical exercise intervention studies with cancer patients. Surg Oncol 2013;22:92-104.

Ulrich RS. How design impacts wellness. Healthc Forum J 1992;35:20-25.

Weiderpass E. Lifestyle and cancer risk. J Prev Med Public Health 2010; 43:459-471.

West MA, Loughney L, Lythgoe D, Barben CP, Sripadam R, Kemp GJ, Grocott MP, Jack S. Effect of prehabilitation on objectively measured physical fitness after neoadjuvant treatment in preoperative rectal cancer patients: a blinded interventional pilot study. Br J Anaesth 2015; 114:244-251.

Wiskemann J, Kuehl R, Dreger P, Schwerdtfeger R, Huber G, Ulrich CM, Jaeger D, Bohus M. Efficacy of exercise training in SCT patients--who benefits most? Bone Marrow Transplant 2014;49:443-448.

Yang EJ, Chung SH, Jeon JY, Seo KS, Shin HI, Hwang JH, Lim JY. Current practice and barriers in cancer rehabilitation: perspectives of Korean physiatrists. Cancer Res Treat 2015;47:370-378.

Zhu W, Timm G, Ainsworth B. Rasch calibration and optimal categorization of an instrument measuring women's exercise perseverance and barriers. Res Q Exerc Sport 2001;72:104-116. 